\title{
Correction to: Explaining firms' earnings announcement stock returns using FactSet and I/B/E/S data feeds
}

\author{
John R. M. Hand ${ }^{1} \cdot$ Henry Laurion ${ }^{2}$ - Alastair Lawrence ${ }^{3} \cdot$ Nicholas Martin $^{4}$ \\ Published online: 19 August 2021 \\ (C) Springer Science+Business Media, LLC, part of Springer Nature 2021
}

\section{Correction to: Review of Accounting Studies https://doi.org/10.1007/s11142-021-09597-6}

The original version of this article unfortunately contained some mistakes in Table 2 and Table 4.

In Table 2, the sentence "One-quarter-ahead guidance surprises are denoted by (GQ), while one-yearahead guidance surprises are denoted by (GA)." is added at the last sentence of the Table 2 caption. In the heading row, the "Analyst forecast Item" was changed to "Item". Also the row that contains the text "Quarterly guidance (GQ) Item" and "Annual guidance (GA) Item" were deleted.

Table 4 in the original paper is a duplicate of Table 6 . With this, Table 4 has been corrected as presented below.

The original paper has been corrected.

The online version of the original article can be found at https://doi.org/10.1007/s11142-021-09597-6

Alastair Lawrence

AlastairLawrence@london.edu

John R. M. Hand

hand@unc.edu

Henry Laurion

Henry.Laurion@colorado.edu

Nicholas Martin

martinn@unc.edu

1 UNC-Chapel Hill, Chapel Hill, NC, USA

2 University of Colorado Boulder, Boulder, CO, USA

3 London Business School, London, USA

4 UNC-Chapel Hill, Chapel Hill, NC, UK 
Table 4 Annual OLS regressions of abnormal 3-day stock returns at firms' earnings announcements (ABRET) on point-in-time consensus analyst forecast surprises and management guidance surprises in the IUF dataset. One-quarterahead guidance surprises are denoted by GQ; one-year-ahead guidance surprises are denoted by GA. Surprises are included in the regressions only when the percentage of analyst-covered firms for which the surprise is present is $\geq 5 \%$ in the earnings announcement year. Intercepts are estimated but not reported; dummies for data-absent forecast errors are included but not reported; $t$-statistics are in parentheses. Data are from sample [2C] in Fig. 1, 1990:Q1-2016:Q4 Panel A: Univariate panel regression of $A B R E T$ on Street earnings surprise (gray) .

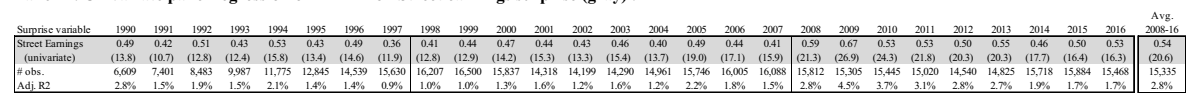

Panel B: Multivariate panel regressions of $A B R E T$ on all 34 non-KPI consensus surprises with annual density $\geq 5 \%$. Significant analyst Street earnings surprises are highlighted in green, forecast surprises other than Street earnings in blue, and management guidance surprises in yellow. This panel shows the 13 forecast surprises with a mean abs $\{t$-stat $\} \geq 1.95$ over 2008-2016. Individual coefficient estimates with abs $\{t$-stat $\}<1.95$ are unhighlighted (white).

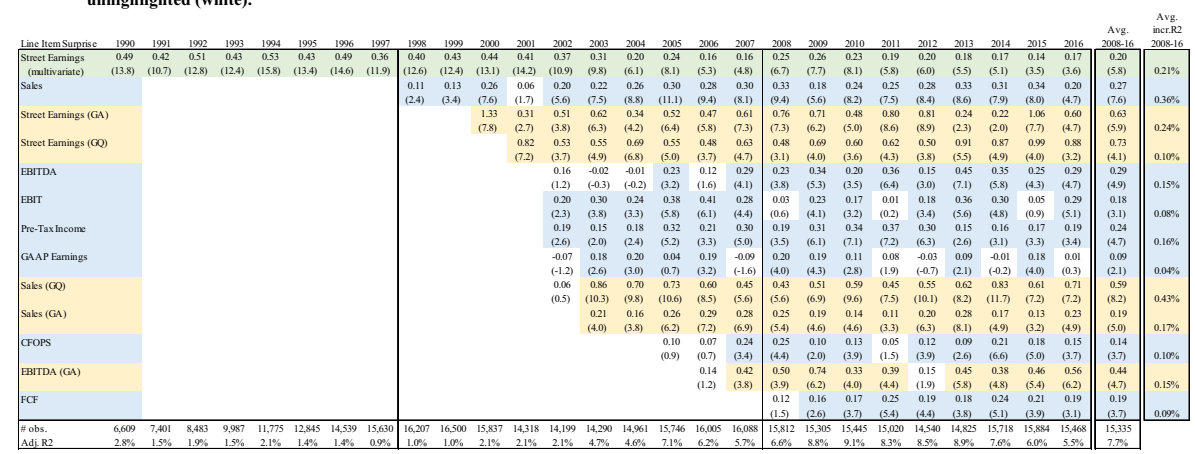

Panel C: This panel shows the 21 forecast surprises with coefficients that have a mean abs $\{t$-stat $\}<1.95$ during 2008-2016 (per table 3, panel B; unhighlighted). Individual coefficient estimates with abs $\{t$-stat $\} \geq 1.95$ are highlighted in blue for analyst forecast surprises and in yellow for management guidance surprises.

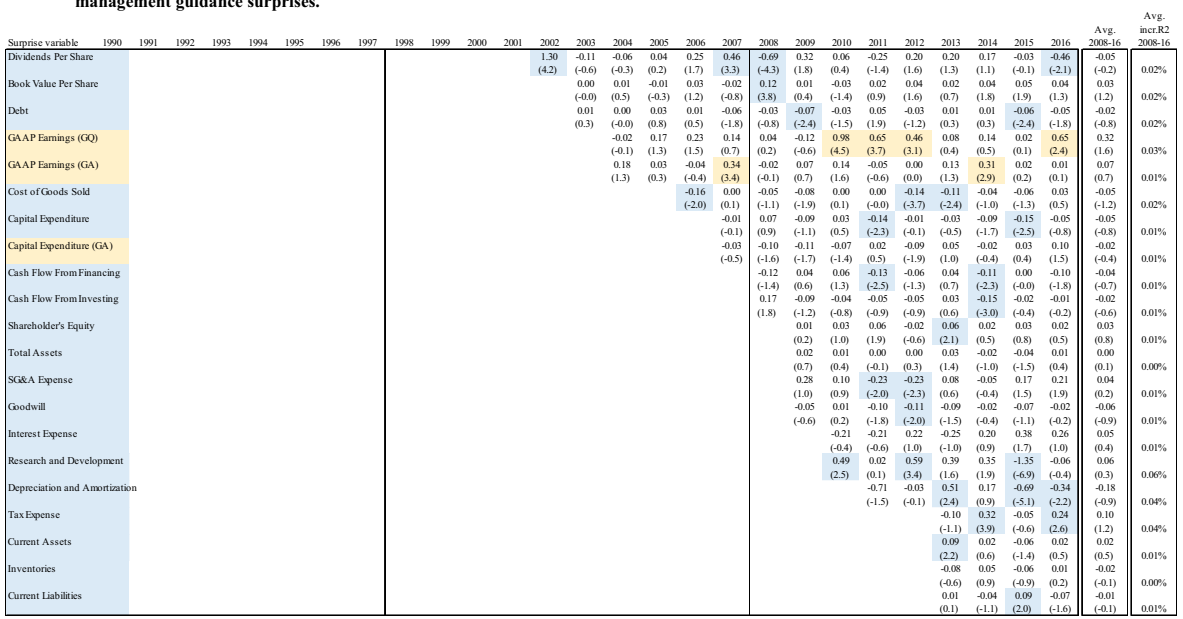

Publisher's note Springer Nature remains neutral with regard to jurisdictional claims in published maps and institutional affiliations. 